\title{
A Survey of \\ Participative Management in California State University Libraries
}

\section{Ellen Gerry and Susan Klingberg}

A survey of librarians in the 19 libraries of California State University was conducted on professional staff participation in decision making, i.e., participative management (PM). The purpose was to gather information on organizational structures which facilitate PM and to assess librarians' perceptions of its degree and effectiveness. Variables were identified which have significant associations with high PM, for example, the existence of a library faculty governance group and the use of committees. Based on the existence of these variables, it is possible to predict whether a librarian is likely to perceive a high or low degree of participative management.

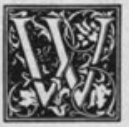

ith the assistance of a research grant, a survey by questionnaire was conducted on the participation of California State University librarians in decision making. The purpose of the survey was two-fold: 1) to determine the degree and effectiveness of librarians' participation in decision making as perceived by the respondents, and 2) to develop a descriptive profile of California State University (CSU) librarians.

In the professional literature, the term participative management is generally used to refer to staff participation in decision making. In this discussion, it will also be used in this sense. However, the term was not used in the questionnaire itself, in order to avoid the problem of ambiguous interpretation. The statement at the head of the questionnaire reads "The purpose... . is to secure information on the organizational structure for professional staff participation in decision making and to determine the degree, quality, and effective- ness of such participation as perceived by CSU librarians."

Over the past 15 years, participative management in libraries has been the subject of many editorials, articles, and conference programs. Because staff members in most libraries are organized according to the traditional pyramidal model and decisions on key matters are usually the prerogative of administrative librarians, participative management has been viewed within the profession as a provocative and challenging issue. A possible explanation for the sustained interest in participative management is that it promises increased involvement in decision making to librarians who are operating in a fairly structured, hierarchical organization.

There is, however, a recent trend in academic libraries toward greater participation of nonadministrative librarians in the management of libraries. Signs of this trend include the adoption by libraries of more open organizational models (such as matrix management) and the use of com-

Ellen Gerry is Government Documents Specialist/Reference Librarian at California State University, Dominguez Hills, Carson, California 90747. Susan Klingberg is Head, Education and Social Sciences Library, at the University of Illinois, Urbana, Illinois 61801. 
mittees for key management functions (such as planning and budgeting). Other evidence of the trend can be found in the professional literature and in the conference programs of library associations.

The increased use of participative management techniques may be a response to changing times. Libraries are currently facing a host of pressing new needs which must be met while traditional operations and services are maintained. Yet in many cases, library budgets remain stable or have even been reduced. Given these circumstances, it is timely to consider the organization of libraries and the role of staff in decision making. Libraries are being asked to do more with less; a key question is whether traditional organizational and staffing models will be able to meet this challenge or whether innovation is needed.

Although the incentive for this study comes from broad professional concerns about library organization and management, the survey itself is limited to librarians in the California State University system. CSU librarians are an appropriate survey group for the issue of participativè management because they are a large group and also because they have faculty status. The 19 CSU campuses are publicly funded and are part of the state system of higher education. California State University is the largest baccalaureate-granting system in the nation. In 1983-84 when the survey was conducted, the system conferred 44,375 undergraduate degrees and 9,690 graduate degrees. Its mission places a greater emphasis on teaching than research. Bachelors' and masters' degrees are offered in 200 subject areas. In 1984, for all of the CSU libraries combined, the volume count was $11,070,214$ and the number of professional librarians employed was 395 .

\section{LITERATURE REVIEW}

An extensive literature review on participative management in academic libraries by Nicholas C. Burckel appeared in College $\mathcal{E}$ Research Libraries in 1984. Burckel begins his article by summarizing how the concept of participative management evolved from the human-relations school of man- agement. In the form of an excellent review essay, he then discusses and critiques the literature on participative management in academic libraries published from approximately 1970 to 1984 . He notes that with the exception of studies by Maurice Marchant on university and research libraries and Henry Stewart, Jr., on small colleges, there has been little rigorous analysis of participative management in academic libraries. In addition, he comments on the inconclusive results of those studies. ${ }^{1}$

In his conclusion,(Burckel suggests that participative management techniques are best suited for periods of affluence and expansion and that they should be considered with caution given the fiscal stringencies of the current decade.) He notes that there is no conclusive evidence that participative management influences library effectiveness, but does subscribe to the widely held belief that when properly implemented it increases staff morale and job satisfaction.) Burckel voices a concern that there is at present no accurate method to measure the increased costs of group versus individual decision making. ${ }^{2}$

Because an extensive literature review has been published recently, this discussion will be limited to describing an unpublished study by George R. Lewis that is especially relevant to the CSU study and was not cited by Burckel.

In 1974-75 George R. Lewis administered a questionnaire on participative management to the directors and a sample of professional librarians in $\mathbf{2 4}$ university libraries belonging to the Association of Southeastern Research Libraries (ASERL). ${ }^{3}$ In terms of the number and type of libraries surveyed and the number of respondents, the ASERL and CSU studies are similar. The purpose of the 2 surveys was essentially the same: to determine the practices and perceptions of pro-

\footnotetext{
"The literature review turned up only one survey instrument on participative management in libraries."
} 
fessional staff participation in decision making. The results of the studies are compared in the conclusion.

\section{METHODOLOGY}

\section{Instrument Design}

The literature review turned up only 1 survey instrument on participative management in libraries. It was designed by George R. Lewis. The authors decided to design their own questionnaire, but Lewis was contacted and he granted permission for the use of several of his questions.

The questionnaire was designed to secure information on the organizational structures for librarians to participate in decision making and to determine the degree and effectiveness of such participation as perceived by CSU librarians. The instrument was not designed to support or reject hypotheses; instead, it was developed to answer 5 research questions:

1. What is the demographic profile of librarians employed by California State University (CSU)?

2. What are the organizational structures in the library through which CSU librarians participate in decision making?

3 . What is the degree, quality, and effectiveness of participation in decision making as perceived by CSU librarians?

4. Can participative management be predicted by certain variables?

5 . Which of the organizational structures are associated with a high degree of participative management?

The questionnaire consists of 53 numbered questions, with a blank page where comments on participative management or the survey itself were invited. The first section of the questionnaire includes 14 questions headed "Demographics." Respondents were asked their age, sex, degrees earned, professional organizations, years worked, and number of librarians in their library. For their current position, they were also asked position rank, primary areas of responsibility, and number of staff supervised.

The second section of the questionnaire is headed "Practices and Perceptions." These questions were designed to elicit information about the participation of librar- ians in decision making in their libraries. Questions were formulated according to the premise that certain organizational characteristics influence the degree of participation. Several questions probed opportunities for participation inherent in the organizational structure of the library, e.g., the existence of a library faculty governance group, planning committee, budget committee, etc. Another question addressed how freely information flowed up and down the chain of command. In other questions, librarians were asked about the degree, quality, and effectiveness of their participation in decision making.

\section{Distribution}

The questionnaire was pretested by administering it to the 12 librarians employed at one of the smaller CSU libraries. After some revision, questionnaires were prepared for the 395 CSU librarians holding tenured, tenure-track, or permanent positions. Machine-scorable answer sheets and stamped, self-addressed envelopes were provided with the questionnaires. The answer sheets were precoded by campus. Packets of questionnaires were batched by library and mailed to designated representatives in each library for distribution.

\section{Return Rate}

Announcements in the sponsoring organization's newsletter were used to encourage librarians to participate in the survey. In addition, several weeks after the mailing, a volunteer in each library reminded librarians to return their answer sheets. Of the 395 questionnaires sent out, $247(62 \%)$ were returned. The response rate is shown in table 1.

\section{Analysis}

In order to address the research questions, the survey data were analyzed using the computer software Statistical Package for the Social Sciences (SPSS). First, SPSS was used to create a frequency distribution based on the responses to each question. Then, in order to answer the first question, a profile of the average respondent was developed by using a fre- 
TABLE 1

SURVEY RESPONSE RATE BY CAMPUS

\begin{tabular}{lccc}
\hline \hline Campus & No. Respondents & No. Surveys Sent & \% Responding \\
\hline Bakersfield & 5 & 7 & 71 \\
Chico & 12 & 24 & 50 \\
Dominguez Hills & 12 & 12 & 100 \\
Fresno & 21 & 25 & 84 \\
Fullerton & 12 & 26 & 46 \\
Hayward & 12 & 16 & 75 \\
Humboldt & 8 & 9 & 49 \\
Long Beach & 14 & 33 & 67 \\
Los Angeles & 14 & 21 & 73 \\
Northridge & 22 & 30 & 64 \\
Pomona & 9 & 14 & 83 \\
Sacramento & 19 & 23 & 75 \\
San Bernardino & 6 & 8 & 58 \\
San Diego & 21 & 36 & 34 \\
San Francisco & 11 & 32 & 65 \\
San Jose & 22 & 34 & 52 \\
San Luis Obispo & 15 & 27 & 60 \\
Sonoma & 6 & 10 & 71 \\
Stanislaus & 5 & 7 & 100 \\
Calexico & 1 & 1 & (average response \\
Totals & 247 & 395 & rate $=62 \%)$ \\
& & & \\
\hline
\end{tabular}

quency distribution of responses to specific questions as indicated in table 2 . For the purpose of this survey, the average is an arithmetic mean based on a cumulative frequency count for each question.

\section{FINDINGS}

A demographic profile of CSU librarians was developed by asking questions about age, gender, number of years worked in the library, professional memberships, and supervisory responsibilities. This profile is summarized in table 2.

In 1983 collective bargaining was instituted in the 19-campus CSU system. CSU librarians holding academic rank have faculty status and are included in the same bargaining unit as the teaching faculty. ${ }^{4}$ This unit is represented by the California Faculty Association (CFA), a National Education Association affiliate. The CFA unit of CSU is one of the largest faculty units in the United States. The similarity in the status of teaching faculty and librarians encouraged the researchers to examine the practice of rotating or electing department chairs. The majority of teaching faculty at CSU rotate or elect their department chairs. However, the survey revealed that this is clearly not the trend in CSU li- braries: $75 \%$ of the librarians reported no such practice. Ten percent responded that their library had only 1 department with an elected head or chair, and the remaining $15 \%$ indicated that they have 2 or more departments utilizing the rotating department-chair concept.

"The second research question concerned the identification of organizational structures associated with participative management."

The second research question concerned the identification of organizational structures associated with participative management. One survey question (question 15) asked the respondents to report whether or not their library had a library faculty governance group. In CSU libraries, these groups are representative assemblies typically comprised of all nonadministrative librarians. Although library faculty groups operate somewhat differently on each campus, they primarily exist to facilitate self-governance and 
TABLE 2

DEMOGRAPHIC PROFILE OF CSU LIBRARIANS:

FREQUENCY DISTRIBUTION OF SELECTED QUESTIONS

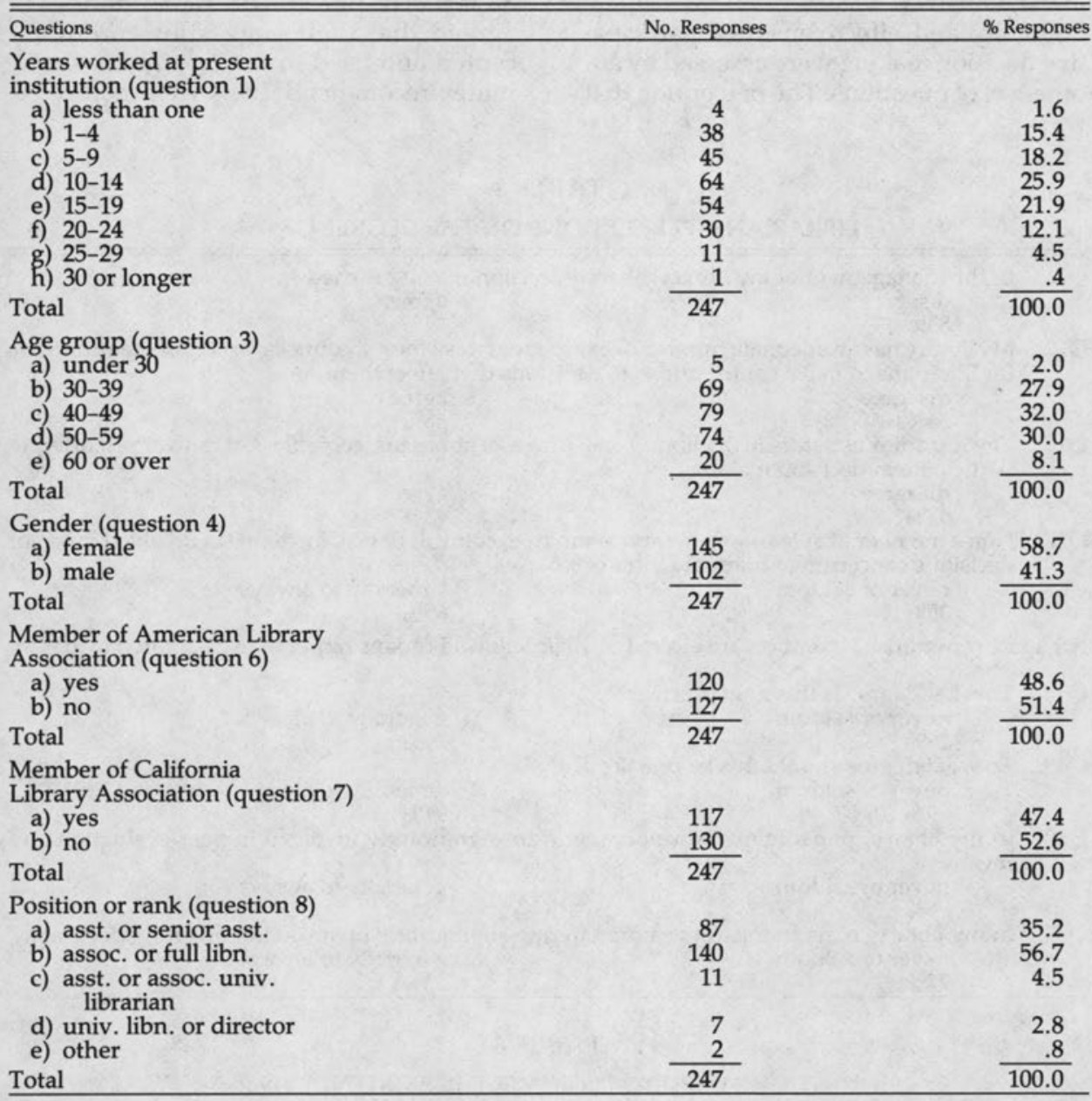

are comparable to an academic senate. Slightly more than $50 \%$ of the respondents affirmed the existence of a library faculty group in their library. Another question (question 27) asked respondents to report their membership on a library committee, council, or task force with major policy responsibility. Nearly $35 \%$ reported very little or no involvement with such a group.

Several of the survey questions addressed the third research question which asked librarians' perceptions of the degree, quality, and effectiveness of participation in decision making. The degree of participation was analyzed by questions asking for perceptions about the existence of shared decision making; whether there was an adequate number of committees for librarian participation; the encouragement of participation by top administrators; membership on decision-making bodies; election versus appointment of librarians to committees; and involvement 
in peer evaluation and budget decisions. Table 3 shows the responses to these questions regarding degree of participative management.

Quality and effectiveness of participative decision making were assessed by another set of questions. The perception that participation of librarians in the decisionmaking process contributed effectively to the library's management was reported by $62 \%$. Forty percent of the respondents agreed that their suggestions were accepted and used to the maximum. Committee recommendations were perceived

\section{TABLE 3}

\section{LIBRARIANS' PERCEPTIONS ON THE DEGREE OF PM}

Q26. In the management of my library, shared decision making is used
disagree $55 \%$
agree
$45 \%$

Q22. My library has an adequate number of committees, task forces, councils, and staff organizations for librarians to make contributions to decisions that affect them disagree $34 \%$
agree
$66 \%$

Q19. The top administrators in my library encourage all librarians, regardless of rank or seniority, to participate in decision making
disagree
agree

Q27. I am a member of at least one library committee, council, or task force that is involved in major decisions concerning library practices or policies
never or seldom $35 \%$
generally to always
$65 \%$

For some committees, members are elected by their fellow librarians rather than appointed by library administrators

Q48. To what degree is this now practiced?

\section{never or seldom $29 \%$}

Q49. To what degree should this be practiced? never or seldom $9 \%$ generally to always
$71 \%$

generally to always $91 \%$

Q50. In my library, nonadministrative librarians are significantly involved in peer evaluation and review never or seldom
$5 \%$ generally to always 95\%

Q53. In my library, nonadministrative librarians are significantly involved in budgeting decisions never or seldom $77 \%$ $23 \%$

\section{TABLE 4}

\section{QUESTIONS USED TO INDICATE THE EXISTENCE OF PM}

Q19. The top administrators in my library encourage all librarians, regardless of rank or seniority, to participate in decision making

Q20. The top administrators in my library accept and make maximum use of suggestions made by other librarians

Q25. The participation of librarians in decision making contributes to the effective management of my library

Q26. In the management of my library, shared decision making is used

In dealing with committees and task forces on decisions affecting library policies and procedures, the library administration:

Q35. consults

Q36. requests recommendations

Q37. shares authority

Q38. delegates authority

Q39. Most reasonable committee recommendations are accepted and implemented by library administrators 
as accepted and implemented by $70 \%$ of those responding.

From the perspective of data analysis, the most challenging of the research questions was number 4: Can participative management be predicted by certain variables? In order to address this question, frequencies were determined for all of the survey responses. Then, the questions most likely to indicate the existence of participative management were identified; these questions are displayed in table 4.

A score of participative management (PM) was calculated for each of the 247 respondents. The PM score was derived from the questions in table 4; the formula used was $\mathrm{PM}=\mathrm{Q} 19+\mathrm{Q} 20+\mathrm{Q} 25+\mathrm{Q} 26$ $+\mathrm{Q} 35+\mathrm{Q} 36+\mathrm{Q} 37+\mathrm{Q} 38+\mathrm{Q} 39(\mathrm{Q}$ stands for question). To develop the score, the alternative responses for each of these questions were assigned numbers from 1 for "disagree" or "never" to 4 for "strongly agree," and 5 for "always." Each individual's PM score is the sum of the numbers representing his or her responses to the 9 questions in the PM formula. Because a nonresponse for any of the 9 questions used to calculate PM would have skewed the data, all such nonresponses had to be eliminated from the PM calculations. This process resulted in 217 usable responses. The resulting scores fell between a low score of 9 and a high score of 39 . The range of possible scores was actually 9 to 41 because the number of choices per question varied from 4 to 5 . Table 5 is the frequency distribution of the 217 PM scores.

Because the unit of analysis is the individual respondent, an arithmetic mean of PM (XPM) was computed for individuals' scores and became the number against which each of the questions not included in the calculation of PM was correlated. The XPM was found to be 22.5, the mode 21 , and the median 22.6. PM scores were collapsed into high and low by using the median. Thus, high PM became those scores greater than 22.6, while low PM became any score less than 22.6.

In order to explore the possibility of predicting participative management, as called for in the fourth research question, responses to questions representing inde-
TABLE 5

INDIVIDUAL PM SCORES

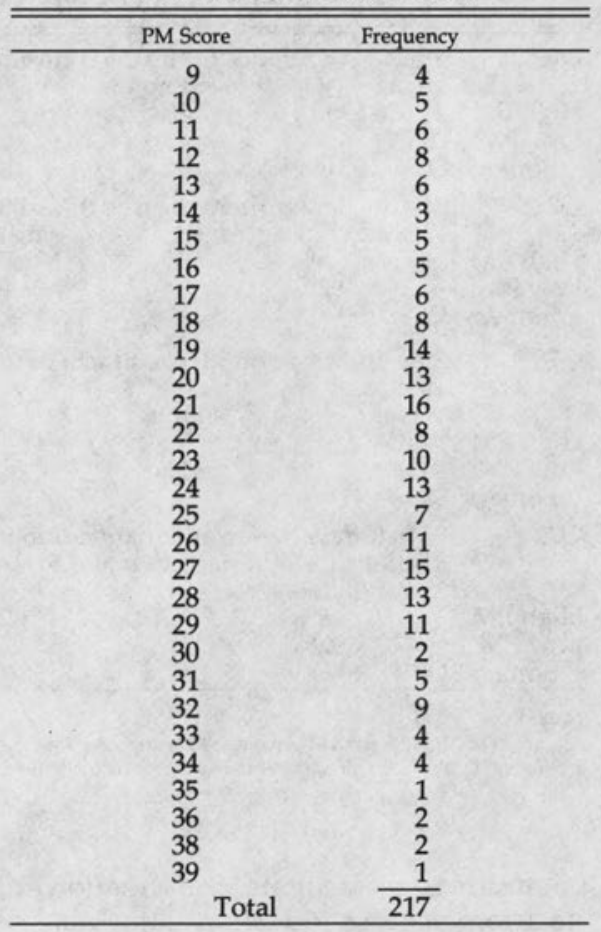

Note: mean of $\mathrm{PM}=22.5$; mode of $\mathrm{PM}=21$; and median of $\mathrm{PM}=22.6$.

pendent variables were tested for their association with PM scores. For example, staff size (question 13) was tested for its predictability with PM by using SPSS to apply Somers' D, a statistical test of association for qualitative data. When Somers' D was calculated, an inverse correlation was found, although the significance was small-negative .116. In other words, librarians from small staffs produced higher PM scores than those from large staffs, with $11.6 \%$ predictability.

Four other independent variables produced substantial positive associations with PM scores. In rank order from high to low predictability, they are: confidence in administrators' decision-making abilities (question 43); free flow of information up and down the chain of command (question 21); committee meetings which are well run and organized (question 28); and the existence of an adequate number of 
TABLE 6

INDEPENDENT VARIABLES PRODUCING POSITIVE ASSOCIATIONS WITH HIGH AND LOW PM SCORES

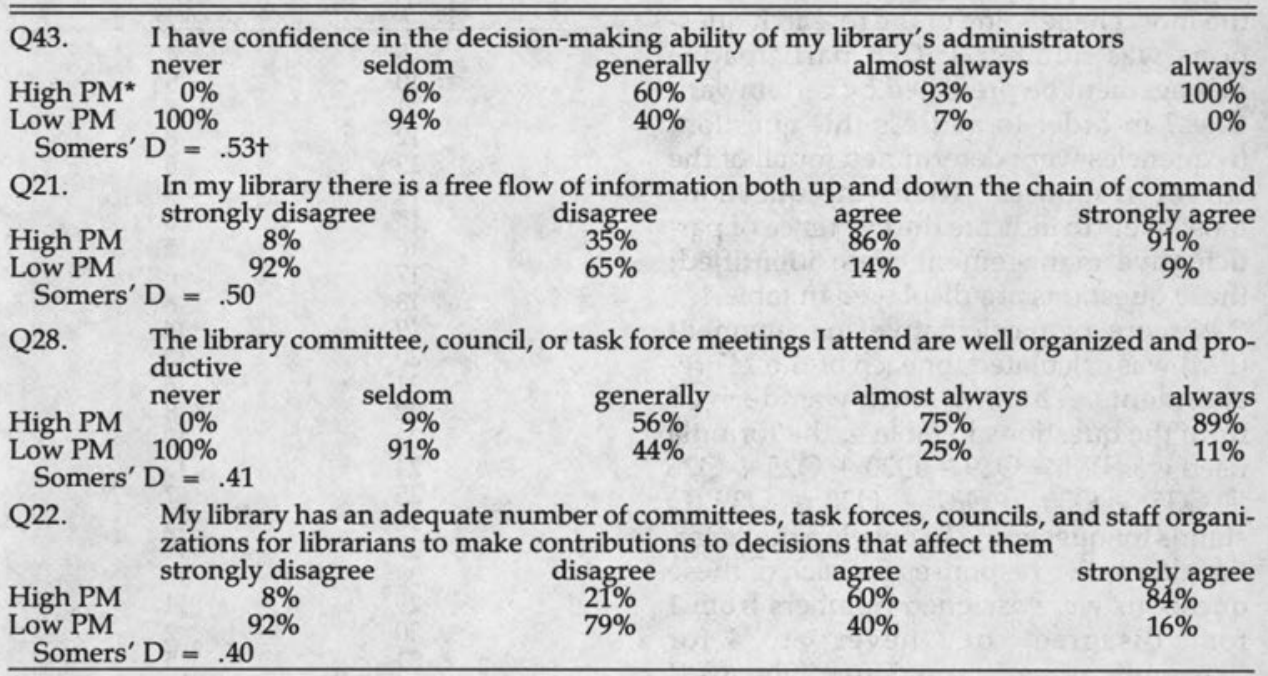

Note:

- Median of 22.6 was used to separate PM scores into high and low.

+ Somers' D shows the predictability of the association between PM and the independent variable.

committees to facilitate participation in decision making (question 22). Table 6 shows the results of the application of Somers' D for these 4 independent variables.

In the last research question, organizational structures such as committees and governance groups were analyzed for their association with PM. Perceptions of the opportunities that 6 typical academic library committees or groups provide for participation in decision making were analyzed. Respondents were given a choice of "not applicable," so the responses are based on perceptions of existing groups. The responses to the 6 questions were then tested for associations with PM by using Somers' D; the results are exhibited in table 7. The 6 groups or committees listed below (in descending order of strength of association) had at least $30 \%$ predictability relative to their positive association with PM: technical services librarians group; budget committee; planning committee; library faculty governance group; public services librari- ans group; and department heads group.

\section{CONCLUSIONS AND IMPLICATIONS FOR THE PROFESSION}

After the data were analyzed, the responses to key questions from the CSU and ASERL surveys were compared to see if the results were consistent. Both surveys asked the following questions using almost the same wording: "Library administrators seek as much input as is reasonably possible before making decisions on library policies and practices, but the final decision is that of the library administrator. To what degree is this now practiced?" (question 46 in CSU survey). Librarians were also asked about their perceptions of what the practice should be. The responses of the two groups are remarkably close; $73 \%$ of CSU librarians and $68 \%$ of ASERL librarians agreed ("generally" to "always") that this is the practice, and $98 \%$ of CSU librarians and $94 \%$ of ASERL librarians thought that this should be the practice. Lewis describes this prac- 
TABLE 7

\section{LIBRARY COMMITTEES AND \\ GROUPS PRODUCING SIGNIFICANT \\ POSITIVE ASSOCIATIONS WITH PM}

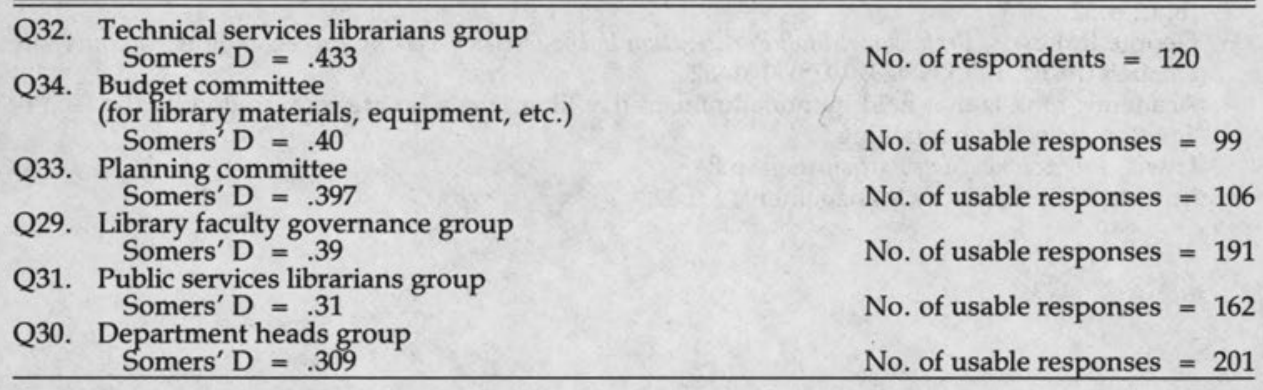

tice as representing a management style that is consultative rather than truly participative, because although staff input is sought, the library administrator makes the final decision.

Both surveys included a question on professional staff participation in decision making and effectiveness. Lewis asked his respondents to characterize the effectiveness of staff participation in decision making. Fifty-eight percent described staff participation as effective or highly effective, while $40 \%$ described it as ineffective. In the CSU survey, the question was stated as: "The participation of librarians in decision making contributes to the effective management of my library," (question 25). The responses on degree of effectiveness for the 2 groups are again very close, within 4 points: $62 \%$ of the CSU librarians answered either "agree" or "strongly agree."

The results of the CSU and ASERL surveys indicate that practices and perceptions of participative management in academic libraries may be similar even in different areas of the country; the two surveys were conducted in the West and in the South. The fact that the two surveys had essentially the same purpose and that the results were consistent with one another supports the conclusion that it is possible to use a questionnaire to measure the degree, quality, and effectiveness of participation in decision making.

In the CSU survey, variables were iden- tified which correlate strongly with high $\mathrm{PM}$. These variables include the existence of a library faculty governance group, the use of committees, and the free flow of information up and down the chain of command. Based on the existence of these variables in a particular library, it is possible to predict whether a librarian is likely to perceive a high or low degree of participative management.

Most observers suggest that participative management increases staff morale and job satisfaction. ${ }^{6}$ The results of this survey can aid library administrators who wish to improve staff morale or who seek simply to create a more open and participative climate. Administrators can facilitate communication up and down the chain of command, develop a structure of committees in key areas, and encourage broad staff participation on committees.) Nonadministrative librarians can breathe new life into existing library faculty groups or, lacking such a body, can take the initiative to organize themselves into a professional staff or faculty governance group. These measures are likely to increase the degree of participative management regardless of the size of the professional staff.

Editorial note: The authors wish to acknowledge the California State University Librarians Chapter of the California Library Association for supporting this survey. 


\section{REFERENCES AND NOTES}

1. Nicholas C. Burckel, "Participatory Management in Academic Libraries: A Review," College \& Research Libraries 45:27-28 (Jan. 1984).

2. Ibid., p.32.

3. George R. Lewis, Professional Staff Participation in the Decision-making Process in Selected University Libraries (ERIC, ED 139 423, 1975), 161-62.

4. Academic rank is that held by nonadministrative librarians who are represented by the faculty agent in collective bargaining.

5. Lewis, Professional Staff Participation, p.84.

6. Burckel, "Participatory Management," p.32. 